\title{
A COMPARATIVE EVALUATION OF KETAMINE-PROPOFOL VERSUS FENTANYL-PROPOFOL IN TOTAL INTRAVENOUS ANAESTHESIA- A DOUBLE BLIND RANDOMISED CLINICAL TRIAL
}

\author{
Sandhya Pandey1, Suman Gupta², Bhanu Choudhary33, Vibha J. Sakhare ${ }^{4}$ \\ 1Postgraduate Student, Department of Anaesthesia, G. R. Medical College, Gwalior. \\ ${ }^{2}$ Assistant Professor, Department of Anaesthesia, G. R. Medical College, Gwalior. \\ ${ }^{3}$ Professor, Department of Anaesthesia, G. R. Medical College, Gwalior. \\ ${ }^{4}$ Postgraduate Student, Department of Anaesthesia, G. R. Medical College, Gwalior.
}

\begin{abstract}
BACKGROUND

Propofol has emerged as a gold-standard for total intravenous anaesthesia (TIVA) for short surgical interventions but lack of analgesia remains its main shortcoming, therefore it is always combined with an analgesic. Ketamine and fentanyl are the popular analgesic in this context. This study was carried out to compare these drugs with propofol to assess haemodynamic and recovery profile of either combination.

Objective- To evaluate quality and compare haemodynamic variability of anaesthesia among the patients scheduled for short surgical procedures in ketamine-propofol and fentanyl-propofol groups.
\end{abstract}

\section{MATERIALS AND METHODS}

In this study, hundred consenting patients undergoing short elective surgeries were divided into two groups of fifty each. Group PF received propofol $2 \mathrm{mg} / \mathrm{kg}$ + fentanyl $2 \mu \mathrm{g} / \mathrm{kg}$ for induction and propofol $4 \mathrm{mg} / \mathrm{kg} / \mathrm{hr}$. + fentanyl $1 \mu \mathrm{g} / \mathrm{kg} / \mathrm{hr}$. for maintenance of anaesthesia and group PK received propofol $2 \mathrm{mg} / \mathrm{kg}+$ ketamine $1 \mathrm{mg} / \mathrm{kg}$ for induction and propofol $4 \mathrm{mg} / \mathrm{kg} / \mathrm{hr}$. + ketamine 1 $\mathrm{mg} / \mathrm{kg} / \mathrm{hr}$. for maintenance of anaesthesia. Haemodynamic variables were recorded pre, intra and postoperatively at regular intervals. At the end of drug infusion(s), time to spontaneous eye opening and response to postoperative questionnaire was noted to assess recovery. All the data presented as mean + standard deviation.

\section{RESULTS}

Patients in both groups did not differ significantly in demographic profile and haemodynamic parameters. Time to spontaneous eye opening was similarly comparable in both the groups $(8 \pm 3 \mathrm{~min}$. and $8 \pm 2 \mathrm{~min}$.) ( $\mathrm{p}=0.53)$. Response to postoperative questionnaire at 30 minutes after anaesthesia was good in both the groups. Incidence of postoperative nausea and vomiting was also statistically insignificant between both the groups. $(p=0.74)$.

\section{CONCLUSION}

Ketamine and fentanyl with propofol infusion for short surgical procedures are equally safe and efficacious. In both groups stable haemodynamics and good recovery profile were noted.

\section{KEYWORDS}

Total Intravenous Anaesthesia, Ketamine, Propofol, Fentanyl.

HOW TO CITE THIS ARTICLE: Pandey S, Gupta S, Choudhary B, et al. A comparative evaluation of ketamine-propofol versus fentanyl-propofol in total intravenous anaesthesia- A double blind randomised clinical trial. J. Evolution Med. Dent. Sci. 2017;6(54): 4094-4097, DOI: $10.14260 /$ Jemds/2017/884

\section{BACKGROUND}

Total intravenous anaesthesia (TIVA) ${ }^{1}$ is defined as a technique of anaesthesia which involves use of intravenous drugs to anaesthetise the patient without the use of inhalational agents. The concept of intravenous (IV) anaesthesia has progressed over a period of time from induction of general anaesthesia to modern day (TIVA) largely due to the better understanding of drug kinetics and dynamics along with the development of intravenous drug delivery systems that are able to titrate and deliver accurately the infusion dose of a given intravenous agent.

Financial or Other, Competing Interest: None.

Submission 13-05-2017, Peer Review 24-06-2017,

Acceptance 29-06-2017, Published 06-07-2017.

Corresponding Author:

Sandhya Pandey,

\#B 13, Dwarikapuri, Fort Road,

Gwalior- 474002, Madhya Pradesh.

E-mail: sbangar1000000@gmail.com

DOI: $10.14260 /$ jemds $/ 2017 / 884$

\section{(c) (i) $($ )}

It was Sigismund Elsholtz who first attempted intravenous anaesthesia in 1665 . In fact, chloral hydrate ${ }^{2}$ was the first anaesthetic agent to be introduced intravenously way back in 1870. Real advance in intravenous anaesthesia took place during 1921 when Daniel and Gabriel ${ }^{2}$ Bardet published their experiences using somnifaine. Fredet and Perlis combined somnifaine with subcutaneous injection of morphine to supplement the effects of somnifaine. To begin with a Vann's $10 \mathrm{~mL}$ syringe was used for this purpose. To facilitate continuous intravenous infusion Abel's syringe 3 was used. Of all the intravenous anaesthetic agents that are available, Propofol's pharmacokinetic profiles favour administration by continuous intravenous infusion. . $^{3,4}$ As Propofol has very little nociceptive effect, it is generally combined with an analgesic, the popular combination being either Propofol with Fentanyl or Propofol with Ketamine. Pain relief to patient is an important constituent of balanced anaesthesia. Ketamine is a potent analgesic; its anaesthetic and analgesic effects have been suggested to be mediated by different mechanisms. It has very high margin of safety, no 
irritation of the veins and no negative influence on ventilation or circulation. Its main disadvantages are that it produces hypertension and precipitates psychomimetic emergence phenomena. ${ }^{5}$ Fentanyl on other hand is the most frequently used opioid in clinical anaesthesia today. Its disadvantage is its negative influence on ventilation and postoperative nausea and vomiting. One of the main drawbacks with Ketamine anaesthesia has been emergence delirium, which Propofol seems to be effective in eliminating.6,7 In this study, the combination of Propofol- Ketamine was compared to the combination Propofol- Fentanyl in patients undergoing general anaesthesia for short elective surgeries. Haemodynamic variables, the time to recovery and patient acceptability were compared.

\section{MATERIALS AND METHODS}

After obtaining approval from ethics committee and well informed written consent, a double-blind study which is randomised (All the drugs were administered by a person not involved in the study) was conducted on 100 patients (as per convenience and sample size was not calculated) of ASA grade I and II (15 to 60 years) of either sex, scheduled for short surgical procedures including suction and evacuation, dilatation and curettage, debridement, close reduction in orthopaedics, skin grafting, incision and drainage of abscess, cyst removal, fibroadenoma excision. Patients were divided into 2 groups PK $(n=50)$ and PF $(n=50)$ as per convenience.

\begin{tabular}{|c|c|}
\hline PK $(\mathrm{n}=50)$ & Ketamine - propofol group \\
\hline PF $(\mathrm{n}=50)$ & Fentanyl - propofol group \\
\hline
\end{tabular}

All patients undergo for minimum investigation as required in individual cases viz. haemogram, blood sugar, blood urea, urine for routine and microscopic examination, ECG, X-ray chest if needed. All patients were kept nil orally for 8 hours before scheduled surgery. All patients were premedicated with injection glycopyrrolate $0.01 \mathrm{mg} / \mathrm{kg}$ body weight intramuscularly (IM) 30 minutes before shifting to Operation room (OR). Upon arrival of the patient in the operation room, intravenous access with two $20 \mathrm{G}$ cannula was established. $500 \mathrm{~mL}$ of crystalloid (Ringer lactate) solution started from one intravenous cannula. Electrocardiogram (ECG) leads placed, noninvasive arterial blood pressure (NIBP), pulse oximetry monitored.

All baseline vital parameters, heart rate, respiratory rate, blood pressure, oxygen saturation $\left(\mathrm{SPO}_{2}\right)$ were monitored. All the drugs, ketamine, propofol and fentanyl were administered by a person not involved in the study to avoid bias. Drugs were given by intravenous route $(\mathrm{I} / \mathrm{V})$ for induction of anaesthesia and by infusion pump for maintenance of anaesthesia. Group PK $(n=50)$ received propofol $2 \mathrm{mg} / \mathrm{kg}+$ Ketamine $1 \mathrm{mg} / \mathrm{kg}$ for induction and propofol $4 \mathrm{mg} / \mathrm{kg} / \mathrm{hr}$. + ketamine $1 \mathrm{mg} / \mathrm{kg} / \mathrm{hr}$. for maintenance of anaesthesia. Group PF $(n=50)$ received propofol $2 \mathrm{mg} / \mathrm{kg}+$ Fentanyl $2 \mu \mathrm{g} / \mathrm{kg}$ for induction and propofol $4 \mathrm{mg} / \mathrm{kg} / \mathrm{hr}$. + Fentanyl $1 \mu \mathrm{g} / \mathrm{kg} / \mathrm{hr}$. for maintenance of anaesthesia. All baseline haemodynamic parameters HR, $\mathrm{SBP}, \mathrm{DBP}, \mathrm{SPO}_{2}$ were recorded before induction and immediately after induction, then every 5 minutes till 30 minutes, then every 10 minutes till the end of procedure and every 10 minutes till 30 minutes postoperatively. The incidence of postoperative nausea and vomiting (PONV) hallucinations, hypertension, hypotension, tachycardia, bradycardia, chest wall rigidity, nystagmus, myoclonic movements were monitored and were managed accordingly, recovery profile was assessed. Patient's satisfaction was assessed using a 100-mm visual analogue scale (VAS) $(0=$ least satisfied, $100=$ most satisfied). The patients rated their satisfaction by making a vertical mark on the $100-\mathrm{mm}$ line. Only patients with score $\geq 75$ were considered satisfied. The exact question was "Are you satisfied with your sedation?" The following questions were asked after 30 minutes of surgery.

- What is your name?

- Where do you live?

- What is date today?

- What is present time?

- Are you having pain?

Obtained data were tabulated and subjected to statistical analysis like student's t-test and chi-square test by SPSS-17 software. The p- value $>0.05$ was taken to be statistically insignificant and p- value $<0.05$ taken statistically significant.

\section{RESULTS}

Demographic Data among both the groups were comparable for mean age, weight and sex ratio. $P$ value $(\geq 0.05)$ is nonsignificant. (Table no. 1).

Values of pulse rate are shown as mean \pm SD. P value $\geq$ 0.05 , is not significant, there was no statistically significant change in pulse rate perioperatively (Table No. 2).

Changes in systolic blood pressure ( $\mathrm{mmHg}$ ): Value are shown as mean \pm SD. At basal level, there was no significant difference statistically. There was statistically significant fall in systolic blood pressure after induction in Propofol Fentanyl group. P value is 0.0001 is highly significant. After starting the infusion systolic blood pressure did not show any significant difference. (Table No.3).

Changes diastolic blood pressure $(\mathrm{mmHg})$ : Value are shown as mean $\pm \mathrm{SD}$. At basal level, there was no significant difference statistically. It was observed that mean diastolic blood pressure before induction were $77.88 \pm 7.04 \mathrm{mmHg}$ and $78.72 \pm 3.87 \mathrm{mmHg}$ in $\mathrm{PK}$ and $\mathrm{PF}$ group respectively. After induction DBP did not show any significant difference in both the groups. $\mathrm{P}$ value $\geq 0.05$ is non-significant. (Table No.4). There is no statistically significant difference in $\mathrm{SpO}_{2}$ (\%) among both groups during various stages of surgical procedure. $P$ value is $\geq 0.05$ statistically insignificant (Graph 2).

\begin{tabular}{|c|c|c|c|c|}
\hline \multicolumn{2}{|c|}{ Variables } & $\begin{array}{c}\text { Group PK } \\
(n=50)\end{array}$ & $\begin{array}{c}\text { Group PF } \\
(n=50)\end{array}$ & $\begin{array}{c}\text { P } \\
\text { Value }\end{array}$ \\
\hline \multicolumn{2}{|c|}{ Age(yrs.) } & $31.10 \pm 12.31$ & $29.74 \pm 11.21$ & 0.546 \\
\hline \multicolumn{2}{|c|}{ Weight(kg) } & $53.48 \pm 8.06$ & $52.46 \pm 7.69$ & 0.494 \\
\hline \multicolumn{2}{|c|}{$\operatorname{Sex}(m / f)$} & $16 / 34$ & $18 / 32$ & 0.079 \\
\hline $\begin{array}{c}\text { ASA } \\
\text { Grade }\end{array}$ & II/I & $10 / 40$ & $05 / 45$ & 0.090 \\
\hline
\end{tabular}




\begin{tabular}{|c|c|c|c|c|}
\hline \multicolumn{2}{|c|}{ Time } & $\begin{array}{c}\text { Group PK } \\
(n=50)\end{array}$ & $\begin{array}{c}\text { Group PF } \\
(n=50)\end{array}$ & $\begin{array}{c}P \\
\text { value }\end{array}$ \\
\hline \multicolumn{2}{|c|}{ Before induction } & $79.02 \pm 3.10$ & $77.96 \pm 3.14$ & 0.089 \\
\hline \multicolumn{2}{|c|}{$\begin{array}{l}\text { Immediate after } \\
\text { induction }\end{array}$} & $81.24 \pm 4.03$ & $80.52 \pm 2.13$ & 0.237 \\
\hline \multicolumn{2}{|c|}{5 Minutes } & $83.10 \pm 5.34$ & $82.32 \pm 2.59$ & 0.360 \\
\hline \multicolumn{2}{|c|}{10 Minutes } & $84.40 \pm 4.86$ & $83.80 \pm 5.16$ & 0.561 \\
\hline \multicolumn{2}{|c|}{15 Minutes } & $84.98 \pm 4.41$ & $83.68 \pm 2.78$ & 0.088 \\
\hline \multicolumn{2}{|c|}{20 Minutes } & $84.48 \pm 4.17$ & $83.24 \pm 2.64$ & 0.082 \\
\hline \multicolumn{2}{|c|}{25 Minutes } & $82.68 \pm 3.58$ & $81.72 \pm 2.21$ & 0.103 \\
\hline \multicolumn{2}{|c|}{30 Minutes } & $79.24 \pm 2.76$ & $78.52 \pm 2.27$ & 0.121 \\
\hline \multirow{4}{*}{$\begin{array}{c}\text { After } \\
\text { Recovery }\end{array}$} & $\begin{array}{c}\text { End of } \\
\text { Procedure }\end{array}$ & $76.48 \pm 3.06$ & $77.22 \pm 2.29$ & 0.213 \\
\hline & 10 Min. & $74.76 \pm 5.92$ & $75.84 \pm 2.09$ & 0.262 \\
\hline & 20 Min. & $74.04 \pm 6.12$ & $74.28 \pm 1.80$ & 0.799 \\
\hline & 30 Min. & $73.56 \pm 4.20$ & $73.32 \pm 1.54$ & 0.729 \\
\hline
\end{tabular}

\begin{tabular}{|c|c|c|c|}
\hline Time & $\begin{array}{c}\text { Group PK } \\
(n=50)\end{array}$ & $\begin{array}{c}\text { Group PF } \\
(n=50)\end{array}$ & P value \\
\hline $\begin{array}{c}\text { Before } \\
\text { induction }\end{array}$ & $120.96 \pm 8.24$ & $120.96 \pm 4.18$ & 1.0 \\
\hline $\begin{array}{l}\text { Immediate } \\
\text { After } \\
\text { Induction }\end{array}$ & $119.08 \pm 4.10$ & $114.62 \pm 6.47$ & $0.0001^{*}$ \\
\hline 5 Minutes & $119.48 \pm 4.27$ & $118.22 \pm 2.82$ & 0.128 \\
\hline 10 Minutes & $119.80 \pm 5.09$ & $119.98 \pm 2.60$ & 0.840 \\
\hline 15 Minutes & $119.16 \pm 5.01$ & $118.44 \pm 3.05$ & 0.412 \\
\hline 20 Minutes & $119.04 \pm 4.10$ & $117.72 \pm 2.99$ & 0.078 \\
\hline 25 Minutes & $119.28 \pm 3.30$ & $118.28 \pm 2.28$ & 0.085 \\
\hline 30 Minutes & $119.16 \pm 3.02$ & $119.00 . \pm 1.57$ & 0.730 \\
\hline \multicolumn{4}{|c|}{ After Recovery } \\
\hline $\begin{array}{c}\text { End of } \\
\text { Procedure }\end{array}$ & $120.04 \pm 6.71$ & $120.12 \pm 2.75$ & 0.939 \\
\hline 10 Min. & $120.62 \pm 4.00$ & $118.80 \pm 5.51$ & 0.102 \\
\hline 20 Min. & $119.72 \pm 4.21$ & $119.04 \pm 4.06$ & 0.458 \\
\hline 30 Min. & $118.80 \pm 4.42$ & $119.14 \pm 4.37$ & 0.725 \\
\hline
\end{tabular}
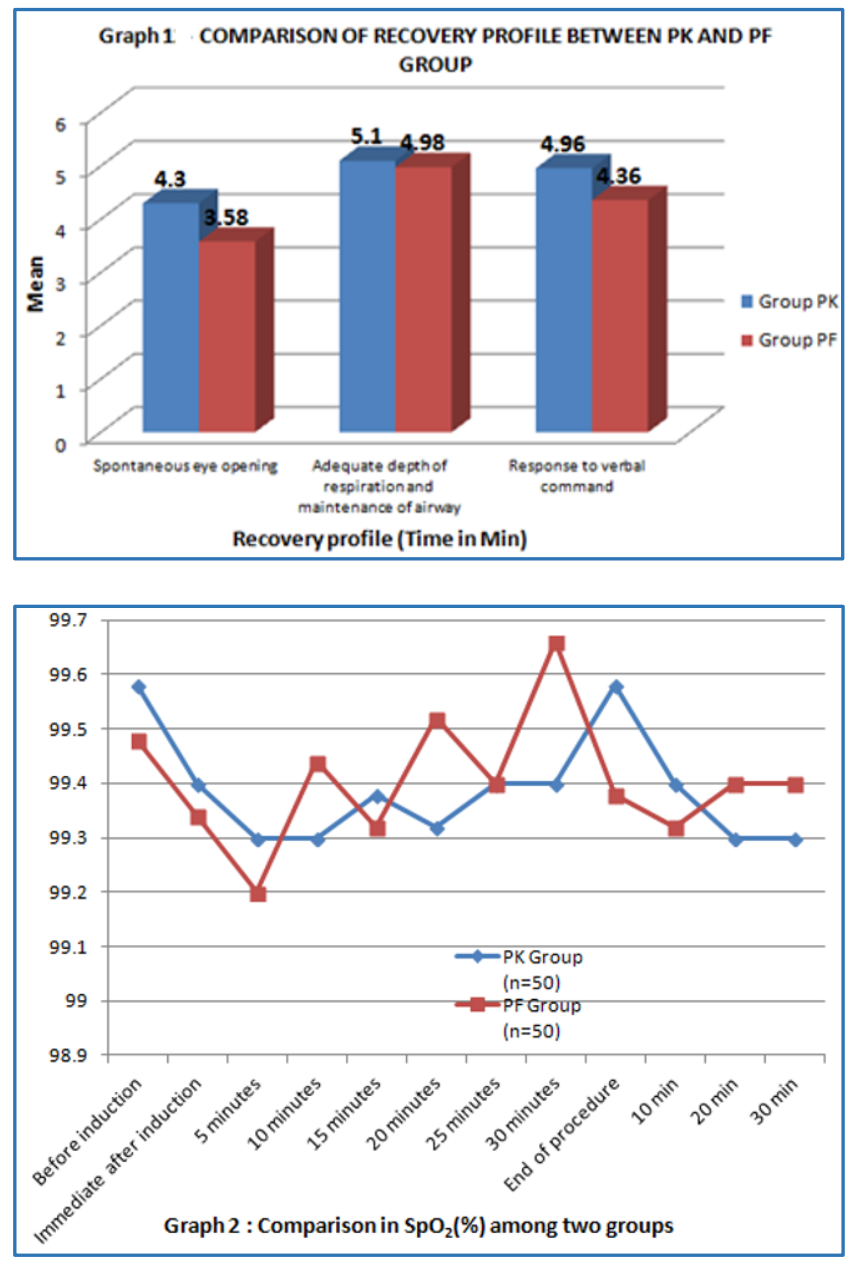

\section{DISCUSSION}

The findings of this study indicate that there was no statistically significant difference among both groups (PK and PF) regarding haemodynamic variability, recovery profile and side effects. R. Mahajan et al $^{1}$ also observed no significant haemodynamic changes among both groups.

Similar results were obtained from other studies.5,8,9,10,11

There was a decrease in mean SBP $(119.08 \pm 4.10)$ and (114.62 \pm 6.47) in $\mathrm{PK}$ and $\mathrm{PF}$ group respectively immediately after induction. Later (mean \pm SD) SBP remained stable among both groups at 5, 10, 15, 20, $25 \mathrm{~min}$. and at the end of procedure. On applying statistical test for intergroup comparison, the difference in SBP was highly significant immediately after induction in $\mathrm{PK}$ group compared to $\mathrm{PF}$ group $(\mathrm{P}=0.0001)$ because propofol and fentanyl had been given IV bolus. Propofol causes hypotension due to its vagotonic effect and fentanyl inhibits baroreceptor reflex. After starting infusion difference in SBP at different time interval was statistically insignificant $(\mathrm{P} \geq 0.05)$. Bajwa S.J.S. et $\mathrm{al}^{3}$ observed that ketamine-propofol provide better control of SBP as compared to propofol-fentanyl. There was significant fall in SBP in PF group after induction $(\mathrm{P} \leq 0.05)$ while there was mild increase in SBP in PK group which is statistically insignificant $(\mathrm{P} \geq 0.05)$. Their findings are well in accordance with our study. Similar results were obtained from other studies. ${ }^{1,5,8,9,10,12,13}$

Vallejo M. C. et al ${ }^{5}$ also observed no statistical significance in their study. Similar results were obtained from other studies. $7,10,14$ 
There was no change in mean respiratory rate in both groups immediately after the induction. After starting the infusion no significant $(\mathrm{P} \leq 0.05)$ changes have been observed in mean RR at 5, 10, 15, 20, 25 min. and at the end of procedure in PK and PF group respectively. On statistical testing for intergroup comparison, the difference in $\mathrm{RR}$ between both groups at different time interval was statistically insignificant $(\mathrm{P} \geq 0.05)$. R. Mahajan et $\mathrm{al}^{1}$ also observed no statistically significant $(\mathrm{P} \geq 0.05)$ difference with respect to respiratory rate among both groups. Similar results were obtained from other studies.5,9,10,15

\section{CONCLUSION}

Following Conclusions are drawn from the Present Study-

- Both ketamine and fentanyl in propofol infusion for short surgical procedures are equally safe and efficacious.

- Infusion of propofol-ketamine and propofol-fentanyl both provides stable haemodynamics and good recovery profile.

- Patient satisfaction is good among both the groups with no significant adverse effects.

\section{REFERENCES}

[1] Mahajan R, Swarnkar N, Ghosh A. Comparison of ketamine and fentanyl with propofol in total intravenous anesthesia. The Internet Journal of Anesthesiology 2009;23(2):1-7.

[2] Thiagarajan B. Total Intravenous Anaesthesia. Stanley Medical College 2014.

[3] Bajwa SJS, Bajwa SK, Kaur J. Comparison of two drug combinations in total intravenous anesthesia: propofol-ketamine and propofol-fentanyl. Saudi J Anaesth 2010;4(2):72-9.

[4] Khutia SK, Mandal MC, Das S, et al. Intravenous infusion of ketamine-propofol can be an alternative to intravenous infusion of fentanyl-propofol for deep sedation and analgesia in paediatric patients undergoing emergency short surgical procedures. 2012;56(2):145-50.

[5] Vallejo MC, Romeo RC, Davis DJ, et al. Propofolketamine versus propofol-fentanyl for outpatient laparoscopy: comparison of postoperative nausea, emesis, analgesia, and recovery. J Clin Anesth 2002;14(6):426-31.
[6] Akin A, Guler G, Esmaoglu A, et al. A comparison of fentanyl-propofol with a ketamine-propofol combination for sedation during endometrial biopsy. J Clin Anesth 2005;17(3):187-90.

[7] Messenger DW, Heather EM, Paul ED, et al. PropofolKetamin: combination has shorter recovery time with similar hemodynamics compared to propofol alone in upper gastrointestinal endoscopy in adult. Acta Medica Mediterranea 2013;29:259.

[8] Willman EV, Andolfatto G. A prospective evaluation of "Ketofol" (Ketamine/Propofol Combination) for procedural sedation and analgesia in the emergency department. Annals of Emergency Medicine 2007;49(1):23-30.

[9] Tosun Z, Esmaoglu A, Coruh A. Propofol-ketamine vs propofol-fentanyl combinations for deep sedation and analgesia in pediatric patients undergoing burn dressing changes. Paediatr Anaesth 2008;18(1):43-7.

[10] Samad MA, Islam MS, Ahmed M, et al. Evolution of ketofol as total intravenous anaesthetic for burn dressing in adult patient. JAFMC Bangladesh. 2012;8:20-4.

[11] Hui TW, Short TG, Hong W, et al. Additive interactions between propofol and ketamine when used for anesthesia induction in female patients. Anesthesiology 1995;82(3):641-8.

[12] Badrinath S, Avramov MN, Shadrick M, et al. The use of a Ketamine Propofol combination during monitored anesthesia care. Anesth Analg 2000;90(4):858-62.

[13] Guit JBM, Koning HM, Coster ML, et al. Ketamine as analgesic for total intravenous anesthesia with Propofol. Anesthesia 1991;46(1):24-7.

[14] Yousef GT, Elsayed KM. A clinical comparison of ketofol versus propofol as an induction agent on quality of laryngeal mask airway insertion and hemodynamic stability in children. Anesth Essays Res 2013;7(2):194-9.

[15] Ramdev B, Sharma DK, Sharma SR, et al. A comparative evaluation of Propofol-Ketamine and Propofol-Fentanyl as T.I.V.A techniques in terms of haemodynamic variables and recovery characteristics in minor surgeries. IOSR-JDMS 2015;14(4):19-26. 